\title{
On Contemporary Female Seal-carving Artists
}

\section{Chenfu Sun}

School of Fine Arts, Nanjing University of the Arts, Nanjing 210013, Jiangsu, China

DOI: $10.32629 /$ asc.v2i4.563

\begin{abstract}
In contemporary times, female art is gradually seen as an independent branch of art. Seal carving is a world intangible cultural heritage and an important part of Chinese art. Female seal-carving artists, against such a backdrop, are exhibiting their own charm with a tint of Chinese characteristics. This paper intends to give an outline of female seal carving in China and its development process. It then explores its artistic features with examples of contemporary female seal-carving artists, such as Luo Pengpeng and Yin Fenghua. In the end the problems confronting the female group will be discussed and their way out.
\end{abstract}

Keywords: contemporary, female, seal carving, calligraphy

Regarding Chinese traditional art — poem, calligraphy, painting and seal, female seal-carving artists were perhaps the fewest. Ancient women often fell into passive learning and accidental acquisition, which was closely linked with seal carving materials, tools, techniques and proficiency. Under the guidance of social norms such as "equality between men and women", the number of female seal-carving artists has gradually grown. This paper starts with ancient female seal carving, and then transitions to contemporary female seal-carving artists such as Luo Pengpeng and Yin Fenghua. From the particular to the general, the paper explores the unique style and charm of contemporary female seal-carving artists and summarizes their artistic features.

\section{Overview of female seal carving}

Seal carving, favored by only a few, is a lonely art. It strikes you as a laborious work. With a stone, a carving knife, you have to bury yourself in the creation, engaging in either drastic or fine crafting. It takes half an hour the fastest to complete or a number of days the slowest depending on whether you are cultured enough in writing and calligraphy, or more importantly, whether you have a keen sense of art. Since ancient times, women have been associated with needlework, so it is hard to imagine that they have knives and stones at their disposal. It seems a bit odd that gentle, delicate women, bent over their desks against windows and oil lamps, could carve hard, stubborn stones with alloy steel knives in their hands. But since women can master a needle and thread, how could they be afraid of knives and stones?

Throughout the history of seal carving, there were only a handful of female seal-carving artists. Seal carving was born later than calligraphy. It was not until the Ming and Qing Dynasties that seal carving became fully recognized by the literati and had strong artistry. Based on the philosophy of "Yin Zong Qin Han" (Those who learn seal carving should first imitate the seals of the Qin and Han Dynasties), seal carving artists, headed by Wen Peng (1498-1573) and He Zhen (15221604), studied new carving methods, with some pursuing exquisiteness and neatness, while others rich changes. While during the two dynasties, the whole society was gripped by the belief that "mediocrity is the virtue of women". Therefore, there were few distinguished female seal-carving artists, and even if there were, they either were wives and concubines of male artists, or simply moved about from one place to another without a steady income. In the latter case, seal carving was reduced to a way of making a living. For instance, Han Yuesu (date of birth and death unknown) was the concubine of Liang Qianqiu (unknown-1637), and Shi Jiu (1848-1917), wife of Wu Changshuo (1844-1927), as well as Sun Jin (1882-1941), the second wife of Wu Shiqian (1867-1922). Yang Ruiyun (date of birth and death unknown) and Jin Sujuan (date of birth and death unknown) are closely related to Wang Qishu (1728-1799), the compiler of Ancient Seals of Feihongtang. They could make a name for themselves in the history because first of all, they were constantly exposed to Wang Qishu's profound knowledge and skill of seal carving. Next, they had a talent for seal carving and were guided by excellent teachers. Lastly, the compilation of seals, with written records, led to their well-knownness. The fact that Wang Qishu compiled the two into the book also served as guidance for and encouragement to later generations of female seal-carving artists. In modern times, female seal-carving artists include Tan Yuese (1891-1976) and Liu Shudu (1899-1985).

The very few female seal-carving artists in history does not mean there were no bright stars such as Han Yuesu (date of birth and death unknown), Yang Ruiyun (date of birth and death unknown), Jin Sujuan (date of birth and death unknown), 
Wen Jingyu (date of birth and death unknown), Zhou Qi (1814-1861), Shi Jiu (1848-1917), Song Zhen (1874-1900) and Sun Jin(1882-1941). It can be seen form the life span of these females that they did not have a big role to play in history, and few people would pay attention to their lives. Firstly, it is about the ancient women themselves. It is difficult for their artistic spirit to awake because they were not well-educated and mostly inferior to men. The second reason regards the social problems in ancient China. The social morality of male superiority was deeply rooted, imposing various constraints on women while historical records of them remain insufficient. Therefore, female seal-carving artists have limited influence on later generations with a small number of followers.

In ancient times, women, being in a passive position in learning seal carving, were usually influenced by their fathers and husbands. Sun Fengtai (date of birth and death unknown) passed on her father's method while Han Yuesu, Song Zhen and Sun Jin were all edified by their husbands. Some were even forced to fill their fathers' or husbands' shoes in seal carving because they were in poor health and could not manage carving.

In modern times, women's status has been rising steadily. After the founding of the People's Republic of China, gender equality was advocated. Women who broke free of feudal shackles gradually took art as a way to express their emotions and reflect their self-value. As a result, female seal-carving artists stepped onto the stage of art and shone brightly.

\section{The artistic features of contemporary female seal-carving artists}

At present, female seal-carving artists are on the rise as women are less burdened by child-bearing and less dependent on men. Women are now actively engaged in seal carving, injecting warmth into originally cold knives and stones. Although more and more women are dabbling in this art, they still do not represent the majority. There are still very few female sealcarving artists, mainly scattered in Henan, Guangdong, Guangxi, Beijing, Shanxi, Jiangsu, Liaoning, Shanghai, Zhejiang and other provinces and cities. The backbone of female seal-carving artists include Luo Pengpeng and Ma Qingyuan from Beijing, Gu Qin from Shanghai, Yin Fenghua and Shen Xiaoying from Shanxi, Wu Ying, Shen Yingli, Lin Ru and Hu Zhaoxia from Zhejiang, Cheng Shaoyan, Yuan Zhaoxia and Li Li from Shandong, Lu Haijiao from Heilongjiang, Gu Jingyun from Inner Mongolia, Sun Xiaoping and Yang Jinning from Chongqing, Zhang You from Hubei, Chen Chunfang Henan, Fang Lingbo and Jiang Xuelian from Jiangsu, and Zhang Lin from Anhui, etc.

Among them, Luo Hao is currently the dean of Chinese Academy of Seal Carving, Chinese National Academy of Arts. She has led delegations to publicize Chinese seal carving on multiple occasions in France, Italy, Australia, Japan, South Korea, Singapore, Malaysia and other countries. In 2007, she helped in establishing China's first postgraduate program of seal carving that took in the first batch of postgraduate students majoring in seal carving, becoming a pioneer in the art as a discipline. On September 30th, 2009, Chinese seal carving became the World Intangible Cultural Heritage. According to Mr. Han Tianheng, "As the person in charge of the application, Luo Pengpeng is always working on the front line. She wrote the application text, the script and commentary of the application video, organized and designed the shots, and searched extensively and verified repeatedly the application materials... ${ }^{[1]}$ In the years following the establishment of Chinese Academy of Seal Carving, she prepared and organized a series of innovative, modern seal carving exhibitions, such as "Exhibition on Chinese Shoushan Stone (a kind of precious stone unique in Fuzhou, Fujian province) Carving", "Seal Carving Exhibition Celebrating the 60th Anniversary of the Founding of the People's Republic of China", etc. In this sense, she devoted herself to raising the popularity of Chinese seal carving in both China and beyond.

Her seal carving style is as refreshing as it is artistic. Figure 1 "Bai Ma Fei Ma (A white horse is not a horse)", one of Luo's carved seals, is indeed an art. There are two same characters "Ma (horse)" in it, with one of them in red and the other in white. Furthermore, the outer frame of the first character "Bai (white)" resembles that of the last character "Ma". Despite the fact that the four characters are framed in the grid, they are not tightly restricted. Every single character is vivid and smart, and the whole seal is coordinated and unified. Figure 2 "Fa Bu E Gui (The law cannot fawn on the noble)" is a red seal. Although the characters are also confined in the grid, the strokes are integrated with the boundaries, free from an abrupt impression. The seal script is in a simple and clear style, following the principles of "less is more" and "be to the point".

Figure 3 "Jian Yi Yang Min (Be thrift to support the people)" and Figure 4 "Tian Chi (a heavenly lake)" are both in white, but with different features. Looking at Luo Pengpeng's seals, the author finds that her carving style changes accordingly with the content. This is not only her artistic view, but also the uniqueness of her seal carving. For example, "Bai Ma Fei Ma", as a Chinese idiom, talks about sophistry parodoxes. To echo its meaning, the last character "Ma" is carved in a way that is similar in structure to the first character "Bai". It is also in white to echo "Bai Ma (white horse)". The carving of "Fa Bu E Gui" is neat and solemn, with strict strokes arranged tidily within the boundary. The strokes of "Fa Bu E Gui" are short and strong, leaving more blank space. A sense of simplicity will grip you, as well as diligence and frugality. The character "Tian (heaven)" in "Tian Chi" breaks its upper boundary as if it is connected with the heaven. The left component of the character 
"Chi (lake)" are shaped as water ripples as well as a pool of spring water. In the seals carved by Professor Luo, women's sensitive thoughts are embedded to provoke pondering. It is commendable that individual marks can be integrated with the artistic features of seals.
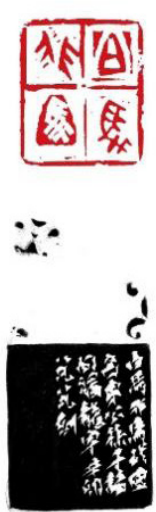

Figure 1. "Bai Ma Fei Ma"
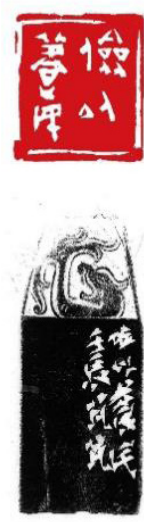

Figure 3. "Jian Yi Yang Min"
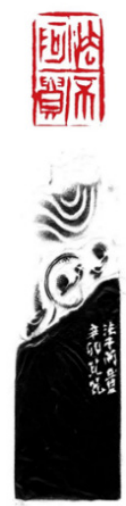

Figure 2. "Fa Bu E Gui"
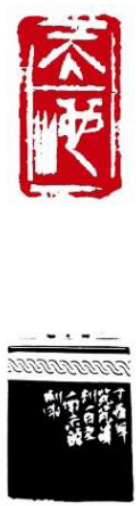

Figure 4. "Tian Chi"

Yin Fenghua, the president of Jinyang Association of Seal Carving, is another contemporary female seal-carving artist who has made great achievements. As an outstanding practitioner in modern seal carving, she was known for her "General Seal (one of the official seals of the Han Dynasty)" in her early days. With proficient and coordinated use of forward-pushing carving (a seal-carving method that carves lines on stones by pushing forward the knife) and pressing carving (another sealcarving method that carve lines by repeatedly pressing the knife into the stone), rich changes can be seen in a very limited space, producing seals of a modern style. In commenting her carving "Da Feng Qi Xi Yun Fei Yang"(A gale has risen and is sweeping the clouds across the sky), Zhu Tianshu says "The carving is natural and character changes are well controlled, leaving a deep impression."[2]

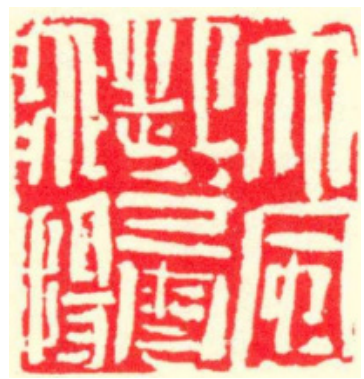

Figure 5. "Da Feng Qi Xi Yun Fei Yang"

In recent years, she has become more proficient in seal carving. She made bold breakthroughs and carved mostly pottery seals. By combining the features of the carving of the imperial edict in Qin Dynasty and eaves tile carvings, brick carvings 
and official seals in Qin and Han Dynasties with the features of modern seals, a unique and lofty style is therefore formed characterized by vigor, strength and also softness in both round and square shapes. The edges of her seals are often blurred with a tint of history, making them more like ancient seals. They can bring viewers back to the era of Qin and Han when carving on bricks and tiles were in their hay day.

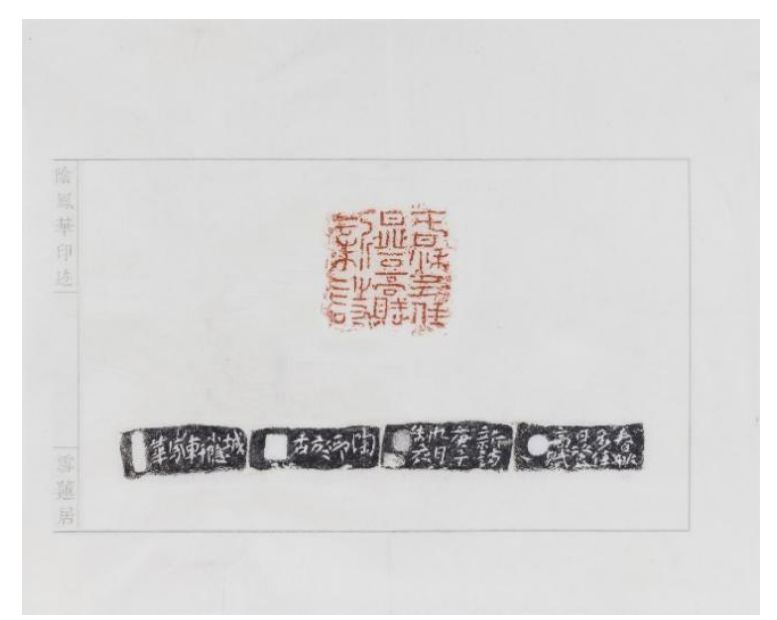

Figure 6. "Chun Qiu Duo Jia Ri, Deng Gao Fu Xin Shi"

(Spring and autumn are lovely seasons in which friends get together to climb up mountains and write poems)

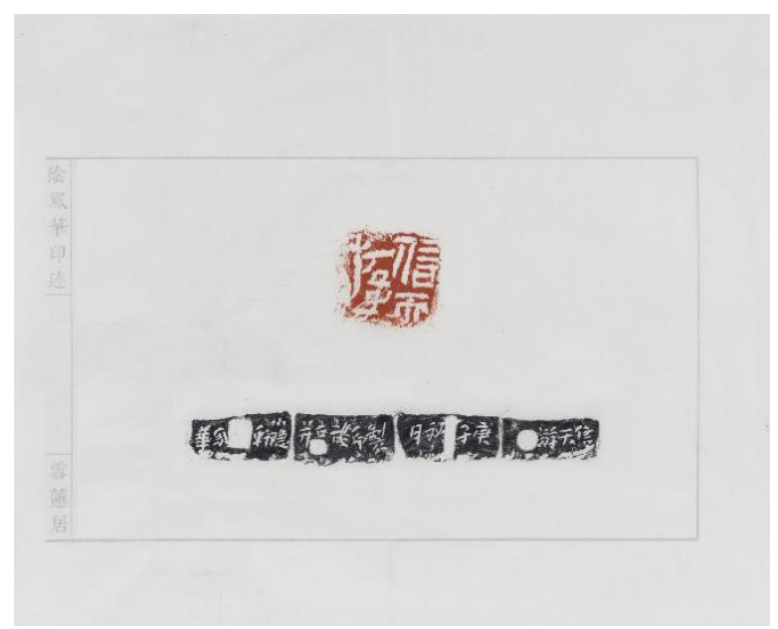

Figure 7. "Xin Tian You" (a kind of Shaanxi local melody)

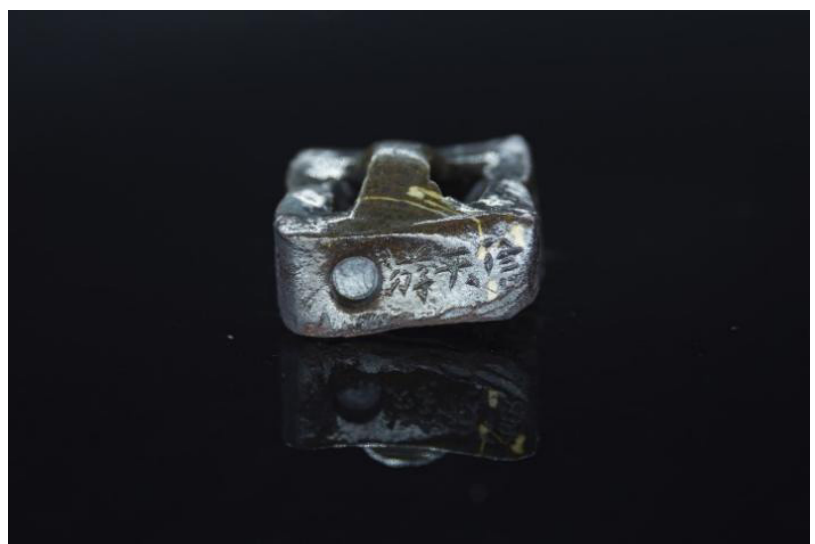

Figure 8. Pottery seal "Xin Tian You"

Yin Fenghua's poems, books, paintings and seals nourish one another. Through flower arrangement, tea tasting, poetry and book reading, her mind and seal carving are truly improved. As the inheritor and practitioner of seal carving with such 
proficiency, she is not only admired by modern women, but also complements what is missing in today's society. Rather than involution and blind compliance, she chooses to roam in the love of her life as who she is by inheriting and spreading art, thus setting an good example for female artists.

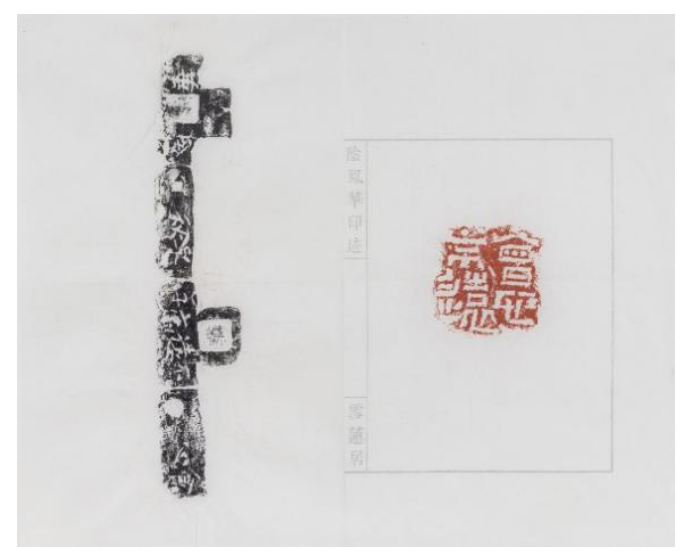

Figure 9. "Hui Xin Bu Yuan" (Understanding is not far away)

Apart from the female seal-carving artists above, there are also many female students majoring in calligraphy and seal carving whose strength should not be underestimated. Higher education of calligraphy and seal carving are growing from strength to strength, represented by such art institutions as Nanjing University of the Arts, China Academy of Art, Central Academy of Fine Arts and Chinese National Academy of Arts, etc. More and more female students, as excellent as their male counterparts, have proved themselves in exhibitions and school associations. These rising stars will eventually become the backbone of the future field of seal carving.

\section{Reflection on the rise of contemporary female seal-carving artists}

With a healthy art environment in the new era, it is inevitable that more and more women will devote themselves to calligraphy and seal carving to maintain the balance of calligraphy and seal carving. However, there are also problems among female seal-carving artists. First of all, they have a similar carving style as their male counterparts. In other words, there are few unique characteristics of women in their works. This has to do with their personalities fostered by today's living environment. Gender equality is advocated in the new era when women are no longer subordinate to men. Therefore, unisex and genderless style are popular, rendering their carving style natural, unrestrained and less feminine. Next, female seal-carving artists always learn from male artists, be it ancient or contemporary ones. Since the art comes down in one continuous line, their seals will inevitably take on a certain degree of their teacher's style. Another explanation regards the exhibition hall culture. Whenever eminent works are selected in major exhibitions, a large number of people will imitate and learn from them. As learning targets, their carving style will for sure last for a certain period of time. As a result, it is difficult to distinguish works of female artists from male artists in an exhibition hall. Secondly, if the same works are labeled with an opposite gender, women's seal carving works will often receive more praise. This is because rare things are more precious and so are carved seals. Despite being a female that may enjoy such a "bonus", the author does not advocate judging the works of art based solely on gender. In fact, the favor over female artists is essentially belittling women. The bonus, in essence, is saying that women cannot always carve better seals than men. This is unfair, both to men and women.

Gender cannot determine the quality of art. It is because of the special background of the times and the personality differences of creators that seal carving presents the different styles between men and women. Drawing lessons from studying contemporary female seal-carving artists is conducive to reflecting on their present situation and helping shape future developments. This is worth in-depth exploration to both female artists and to calligraphy and seal carving.

\section{References}

[1] Tianheng Han. Women Born for Seal Carving — On Luo Pengpeng and Her Art [J]. Chinese Calligraphy, 2013, (03): 27-28.

[2] Tianshu Zhu. On Yin Fenghua's Seal Carving [J]. Calligraphy, 2004, (01): 56-57. 